\title{
Mário Faustino: inovação poética e sentimento agônico
}

Adilson Citelli*

Possui graduação em Letras (1973), mestrado em Literatura Brasileira (1982) e doutorado em Literatura Brasileira (1990), todos pela Universidade de São Paulo. É professor titular do Departamento de Comunicações e Artes da ECA/USP e dos programas de graduação e pós-graduação, em que ministra cursos e orienta dissertações e teses nas áreas de Comunicação e Linguagem, com ênfase nas subáreas: Comunicacão/Educacão, Comunicação/Linguagem. É coeditor da revista Comunicação \& Educação ${ }^{1}$.

E-mail: citelli@uol.com.br

Talvez por sua breve vida e meteórica carreira, ou apenas por não integrar os currículos escolares, Mário Faustino seja pouco conhecido pelas novas gerações e mesmo pelas anteriores. Daí a iniciativa da revista Comunicação $\mathcal{E}$ Educação em publicar, neste número, alguns poemas dele. O nosso autor deixou apenas um livro, $O$ homem e sua hora, no qual os temas "amor e morte, tempo e eternidade, sexo, carne e espírito, vida agônica, salvação e perdição, pureza e impureza, Deus e o homem, passam e repassam, sob diferentes nomes e em diferentes situações" versos apenas publicados em jornais.

Mário Faustino, mesmo não possuindo a notoriedade de outros poetas de sua geração, deixou uma obra marcada pela alta qualidade, tendo influenciado autores, contribuído para orientar os rumos da poesia brasileira e atuado fortemente para divulgar outros poetas, sobretudo os concretistas ${ }^{3}$, impulsionando a criação de uma poesia inovadora pós-geração modernista de 1945. Benedito Nunes, crítico e amigo de Mário Faustino, lembra que após a publicação de Carlos Drummond de Andrade, Jorge de Lima, Cecília Meireles e João Cabral de Melo Neto, a poesia brasileira havia caído em marasmo ${ }^{4}$

O papel de agitador cultural de Mário Faustino foi realizado, especialmente, em página que mantinha no Suplemento Literário do Jornal do Brasil, intitulada Poesia-Experiência, na qual se publicavam poemas e críticas de literatura. O lema da página era "repetir para aprender, criar para renovar". Seguindo o dístico, Mário Faustino dedicava espaço para a boa e alta poesia do passado, assim como para as melhores produções dos novos poetas. Desse mesmo enunciado advinha a sua poesia. Mário Faustino imprimiu técnica clássica ao utilizar o rigor formal através da métrica nos versos e da seleção vocabular rica

* Com a colaboração de Cristine Vargas (revista Comunicação \& Educação - ECA/USP e FFLCH/ USP).

1. NUNES, Benedito. Introdução. In: FAUSTINO, Mário. Poesia de Mário Faustino. Rio de Janeiro: Civilização Brasileira, 1966. p. 5

2. Na história da Literatura brasileira, a poesia concreta foi criada por autores como Décio Pignatari, Haroldo de Campos e Augusto de Campos com o objetivo de mudança, visando a um novo tipo de expressão, baseada em princípios experimentalistas.

3. NUNES, Benedito. Introdução. In: FAUSTINO, Mário. Poesia de Mário Faustino. Rio de Janeiro: Civilização Brasileira, 1966. p. 4.

4. Id. A poesia de meu amigo Mário. In: FAUSTINO, Mário. O homem e sua hora e outros poemas. São Paulo: Companhia das Letras, 2002. p. 52. 
comunicação \& educação • Ano XV • Número 1 • jan/abr 2010

5. AZEVEDO, Reinaldo. Mário Faustino: de volta ao eterno. In: Contra o consenso: ensaios e resenhas. São Paulo: Barracuda, 2005. p. 98.

6. Fonte: NUNES, Benedito. Introdução. In: FAUSTINO, Mário. Poesia de Mário Faustino. Rio de Janeiro: Civilização Brasileira, 1966. p. 1-2. para constituir jogos imagéticos. Para Mário Faustino, a poesia não era apenas fruto de uma explosão criativa e aleatória, sendo necessário que a linguagem a estruturasse. Um dos seus pressupostos era que, quando "a linguagem se organifica, a vida se verbaliza"

Dos temas visitados e revisitados pelo autor, certamente o da morte ocupa destaque em sua poesia. A morte é o ponto de partida e o de chegada de sua angústia poética, e encontra-se entrelaçada ao amor, à vida, ao tempo e ao etéreo. Imagens diversas e assombrosamente belas são tecidas para descrever a morte. Em crítica recente, Reinaldo Azevedo ressalta que "[...] ninguém soube ser tão original na elaboração de figuras, na composição de metáforas de tal sorte únicas, que sua poesia corresponde mesmo a uma reeducação da percepção" ${ }^{6}$. Entretanto, mais assombrosa do que a riqueza da rede imagética tecida por Mário Faustino foi o fato de que a sua obra, de certa maneira, serviu como presságio de uma vida marcada por final rápido e trágico.

\section{VIDA BREVE}

Mário Faustino dos Santos e Silva nasceu no dia 22 de outubro de 1930, em Teresina, Piauí .

Realizou o Ensino Fundamental em sua cidade natal e o Ensino Médio, em Belém do Pará. Com apenas 16 anos debutou no jornalismo ao publicar crônicas e escrever seus primeiros versos. Ingressou na Faculdade de Direito do Pará, mas logo interrompeu o curso, pois havia obtido uma bolsa para estudar Língua e Literatura Inglesa no Pomona College, em Covina, no Estado da Califórnia (EUA), entre 1951 e 1952.

Em 1953, após percorrer a Europa, ocupou o cargo de Chefe da Seção de Divulgação na Superintendência do Plano de Valorização Econômica da Amazônia, permanecendo nele até 1956, ano em que se mudou definitivamente para o Rio de Janeiro. Nessa época, o autor já havia publicado seu único livro de poesia, $O$ homem e sua hora (1955).

De 1956 a 1958, Mário Faustino exerceu a função de professor da Escola de Administração Pública da Fundação Getúlio Vargas. Paralelamente à função, em uma época de intensa atividade literária, dirigiu a página Poesia-Experiência do Suplemento Literário do Jornal do Brasil. Em 1959, como funcionário da ONU, mudou-se para Nova York, onde trabalhou até fins de 1960, quando retornou ao Brasil e retomou as atividades jornalísticas no Rio de Janeiro, no Jornal do Brasil e na Tribuna da Imprensa.

A morte precoce, tema tão invocado pelo poeta em sua obra, ocorreu na madrugada de 27 de novembro de 1962. O autor viajava para o exterior a fim de realizar reportagens para o Jornal do Brasil sobre Cuba, México e Estados Unidos, quando o avião em que estava caiu nos Andes (Peru), em Cerro de las Cruces. Mário Faustino faleceu aos 32 anos de idade. 
Mário Faustino - Adilson Citelli

\section{POESIAS}

\section{Romance}

Para as Festas de Agonia

Vi-te chegar, como havia

Sonhado já que chegasses:

Vinha teu vulto tão belo

Em teu cavalo amarelo,

Anjo meu, que, se me amasses,

Em teu cavalo eu partira

Sem saudade, pena, ou ira;

Teu cavalo, que amarraras

Ao tronco de minha glória

E pastava-me a memória.

Feno de ouro, gramas raras.

Era tão cálido o peito

Angélico, onde meu leito

Me deixaste então fazer,

Que pude esquecer a cor

Dos olhos da Vida e a dor

Que o Sono vinha trazer.

Tão celeste foi a Festa,

Tão fino o Anjo, e a Besta

Onde montei tão serena,

Que posso, Damas, dizer-vos

E a vós, Senhores, tão servos

De outra Festa mais terrena -

Não morri de mala sorte,

Morri de amor pela Morte.

O som desta paixão me esgota a seiva

O som desta paixão me esgota a seiva

Que ferve ao pé do torso; abole o gesto

De amor que suscitava torre e gruta,

Espada e chaga à luz do olhar blasfemo;

O som desta paixão expulsa a cor

Dos lábios da alegria e corta o passo

Ao gamo da aventura, que fugia; 
comunicação \& educação • Ano XV • Número 1 • jan/abr 2010

O som desta paixão desmente o verbo

Mais santo e mais preciso e enxuga a lágrima

Ao rosto suicida, anula o riso;

O som desta paixão detém o sol,

O som desta paixão apaga a lua.

O som desta paixão acende o fogo

Eterno que roubei, que te ilumina

A face zombeteira e me arruína.

\section{Sinto que o mês presente me assassina}

Sinto que o mês presente me assassina,

As aves atuais nasceram mudas

E o tempo na verdade tem domínio

Sobre homens nus ao sol de luas curvas.

Sinto que o mês presente me assassina,

Corro despido atrás de um cristo preso,

Cavalheiro gentil que me abomina

E atrai-me ao despudor da luz esquerda

Ao beco de agonia onde me espreita

A morte espacial que me ilumina.

Sinto que o mês presente me assassina

E o temporal ladrão rouba-me as fêmeas

De apóstolos marujos que me arrastam

Ao longo da corrente onde blasfemas

Gaivotas provam peixes de milagre.

Sinto que o mês presente me assassina,

Há luto nas rosáceas desta aurora,

Há sinos de ironia em cada hora

(Na libra escorpiões pesam-me a sina)

Há panos de imprimir a dura face

À força de suor, de sangue e chaga.

Sinto que o mês presente me assassina,

Os derradeiros astros nascem tortos

E o tempo na verdade tem domínio

Sobre o morto que enterra os próprios mortos.

O tempo na verdade tem domínio,

Amém, amém vos digo, tem domínio 
E ri do que desfere verbos, dardos

De falso eterno que retornam para

Assassinar-nos num mês assassino.

\section{Soneto}

Necessito de um ser, um ser humano

Que me envolva de ser

Contra o não ser universal, arcano

Impossível de ler

À luz da lua que ressarce o dano

Cruel de adormecer

A sós, à noite, ao pé do desumano

Desejo de morrer.

Necessito de um ser, de seu abraço

Escuro e palpitante

Necessito de um ser dormente e lasso

Contra meu ser arfante:

Necessito de um ser sendo ao meu lado

Um ser profundo e aberto, um ser amado.

\section{O mundo que venci deu-me um amor}

$\mathrm{O}$ mundo que venci deu-me um amor,

Um troféu perigoso, este cavalo

Carregado de infantes couraçados.

$\mathrm{O}$ mundo que venci deu-me um amor

Alado galopando em céus irados,

Por cima de qualquer muro de credo,

Por cima de qualquer fosso de sexo.

$\mathrm{O}$ mundo que venci deu-me um amor,

Amor feito de insulto e pranto e riso,

Amor que força as portas dos infernos,

Amor que galga o cume ao paraíso.

Amor que dorme e treme. Que desperta

E torna contra mim, e me devora

E me rumina em cantos de vitória... 
comunicação \& educação • Ano XV • Número 1 • jan/abr 2010

\section{REFERÊNCIAS BIBLIOGRÁFICAS}

AZEVEDO, Reinaldo. Mário Faustino: de volta ao eterno. In: Contra o consenso: ensaios e resenhas. São Paulo: Barracuda, 2005.

FAUSTINO, Mário. O homem e sua hora e outros poemas. São Paulo: Companhia das Letras, 2002.

NUNES, Benedito. Introdução. In: FAUSTINO, Mário. Poesia de Mário Faustino. Rio de Janeiro: Civilização Brasileira, 1966.

. A poesia de meu amigo Mário. In: FAUSTINO, Mário. O homem e sua hora e outros poemas. São Paulo: Companhia das Letras, 2002. 